\title{
Quantitative Alterations of the Commensal Eye Bacteria in Contact Lens Wear
}

\author{
D. F. P. LARKIN ${ }^{1}$ and J. P. LEEMING ${ }^{2}$ \\ Bristol
}

\begin{abstract}
Summary
A study was performed on the commensal external eye flora in 34 long-term contact lens wearers and a matched control group, in order to identify the effect of lens wear. Samples were taken from the lid margin and conjunctiva by semi-quantitative, and tear film by quantitative methods. Cultured bacteria were identified with particular attention to coagulase-negative staphylococci. No qualitative alteration in the commensal bacteria was found, although lens wearers were found to have a significantly higher number of species at all sites than controls. Significant quantitative changes were identified on the lid margin, with particularly high counts in some lens wearers, and tear film. Increased numbers of bacteria obtained from the conjunctiva were not statistically significant. Quantitative changes in the tear film are thought to be secondary to changes at the lid margin, for which no explanation is apparent.
\end{abstract}

Several bacteriological investigations of normal human eyes have demonstrated that the flora of the conjunctiva is qualitatively similar to that of the lid margins, although viable microbial counts may be considerably lower on the conjunctiva. ${ }^{1,2}$ The bacteria isolated (coagulase positive and negative staphylococci, coryneforms, micrococci, and less commonly $\alpha$-haemolytic streptococci and various Gram-negative bacteria) are typical of areas of skin with a high humidity. ${ }^{3}$ It is likely that microorganisms found on the lid margin and conjunctiva represent transient residents rather than autochthonous populations. ${ }^{1}$

The possibility that contact lens wear disturbs the ecology of the conjunctiva has been investigated previously. These studies report similar types of bacteria in lens wearers and normal subjects; $;^{4-7}$ however an increase in Gram-negative organisms in lens wearers has been found in two studies. ${ }^{8,9}$ There is some evidence that whilst conjunctival bacterial counts are suppressed in the first few months of lens wear, they may rise to levels higher than control subjects after six months wear. ${ }^{4,8}$ There are no quantitative data for conjunctival microbial carriage in long-term lens wearers. Acanthamoeba is a recently recognised cause of devastating keratitis in lens wearers ${ }^{10,11}$ and we were interested in the possibility that one factor contributing to the increased susceptibility of long-term contact lens wearers to this condition might be high bacterial populations on the external eye, especially because the appetite of Acanthamoeba for bacteria is the basis for their in vitro isolation and culture.

We therefore instigated a survey of bacterial carriage on the conjunctiva, lid margin and tear film of lens wearers and a matched control group. The 'quantitative' swab procedure introduced by Cagle and Abshire ${ }^{12}$ was used for lid margin and conjunctiva sample

From ${ }^{1}$ University Department of Ophthalmology, Bristol Eye Hospital, and ${ }^{2}$ Department of Microbiology, Bristol Royal Infirmary, Bristol, United Kingdom.

Correspondence to: Mr D. F. P. Larkin, Moorfields Eye Hospital, City Road, London EC1V 2PD. 
collection: this is in fact a semi-quantitative method. Five $\mu \mathrm{L}$ samples were collected for quantitative analysis of tears. The term 'quantitative' is used below to describe numerical analysis of bacteria at each site, although strictly correct only for tear film examination.

\section{Patients and Methods}

Patients: Thirty-four asymptomatic contact lens wearers were recruited. None had a history of eye disease and all had been using daily-wear lenses for correction of refractive error only, for at least 12 months (range 12 months -24 years, mean 8.4 years). This group comprised 18 soft lens wearers and 16 who used either hard or rigid gas-permeable lenses. Patients complied with instructions on lens hygiene and all had disinfected their lenses on the day of sample collection. Soft lens wearers used hydrogen peroxide, chlorhexidine, thiomersal or halazone for disinfection; hard or gas-permeable lens wearers used chlorhexidine, thiomersal, benzalkonium chloride or chlorbutol. The group consisted of 12 males and 22 females, age range 21-51 (mean 30) years. A group of 34 control, non-lens wearing subjects were also studied. These were also asymptomatic and had no history of external eye infection. The control group comprised 11 males and 23 females, age range 19-44 (mean 27) years.

Slit-lamp examination of the external eye was undertaken to exclude clinical abnormality prior to sample collection. Contact lenses were not removed at the time of sample collection and had been worn four to eight hours on that day.

Sample collection: Six samples were taken from each patient: one from each lower lid margin, inferior tarsal conjunctiva and inferior forniceal tear film. All samples were taken and processed by the same person.

A calcium alginate swab (Medical Wire and Equipment Co, Corsham, England) moistened in sterile normal saline, was used to collect lid margin samples. The swab was rubbed from the lateral to medial end of the everted lid margin, and the swab then placed in a sterile tube containing $0.1 \mathrm{ml}$ peptone water. The swab procedure was repeated for sampling of the inferior tarsal conjunctiva. Five $\mu l$ of tear fluid was collected from the inferior fornix with a sterile calibrated glass sampling pipette (Corning Scientific Products, Corning, New York). Care was taken to avoid corneal contact and reflex tear secretion by instructing the patient to gaze superiorly at time of sampling. The tear fluid was then expressed from the pipette to a sterile tube containing $0.5 \mathrm{ml}$ peptone water, using a micro-pipetting aid (Micropipex capillary pipetter, Richardsons of Leicester, England).

Laboratory method: A $0.9 \mathrm{ml}$ volume of Calgon Ringer solution (Lab M, Bury, England) was added to each tube containing an alginate swab. Calcium alginate was dispersed by mixing the tube contents on a vortex mixer for two minutes. From each tube containing swabs or tear fluid, $0.4 \mathrm{ml}$ was inoculated on to a plate of heated blood agar (blood agar base (Lab M) supplemented with $10 \%$ defibrinated horse blood) and spread with a glass hockey stick. Plates were incubated in $7 \%$ $\mathrm{CO}_{2}$ for 48 hours.

Colonies were counted and grouped according to colony morphology, Gram reaction, catalase and oxidase production. Staphylococci and micrococci were further subdivided on the basis of furazolidone and novobiocin sensitivity; coagulase, phosphatase and urease production; production of acid from mannitol, trehalose, mannose, maltose, sucrose and xylose, and pattern of growth in tubes of semi-solid thioglycolate medium. ${ }^{13}$ Gram-negative bacilli were identified using commercial microtest systems (API 20E and 20NE; API Laboratory Products, Basingstoke, UK). Counts were expressed as the number of colony forming units (cfu) of a given bacterial group at each site.

Statistical analysis: For the purpose of statistical analysis counts from right and left eyes were treated as independent variables $(n=68$ in each group); counts from eyes of the same individual often differed markedly. The following methods were applied: (1) comparison of the number of different species isolated from each patient was carried out using Student's $t$ test, (2) comparison of the colony counts at equivalent sampling sites was carried out using the Mann-Whitney $U$ test, (3) correlation between bacterial counts obtained from different sites was evaluated by the Spearman Rank Correlation method. The significance level was taken as $5 \%(p<0.05)$. 
Table I. Comparison of the prevalence of bacteria on the lid margin, conjunctiva and tear film of lens wearers and controls. Figures indicate the number of subjects in each group from whom bacteria indicated were isolated

\begin{tabular}{lcc}
\hline Species & $\begin{array}{c}\text { Lens } \text { wearers } \\
(n=34)\end{array}$ & $\begin{array}{c}\text { Controls } \\
(n=34)\end{array}$ \\
\hline Coagulase-negative & & \\
$\quad$ staphylococci & 33 & 30 \\
Staph. aureus & 7 & 2 \\
Corynebacterium spp. & 11 & 6 \\
Micrococcus spp. & 9 & 14 \\
Acinetobacter spp. & 3 & 1 \\
Streptococcus spp. & 2 & 1 \\
Neisseria spp. & 2 & 1 \\
Moraxella spp. & 1 & 2 \\
Pseudomonas spp. & 1 & 2 \\
Bacillus sp. & 1 & - \\
Serratia marcescens & 1 & - \\
Serratia liquifaciens & 1 & - \\
\hline
\end{tabular}

\section{Results}

Species isolated: Organisms were isolated from at least one of the sampling sites in 33 subjects in each group. Most patients in each group had similar flora at each of the six sites sampled, and there was no qualitative difference between the flora in the lens wearing and control groups. The proportion of Gramnegative organisms was similar in both groups. Lens wearers tended to have a larger number of species at all sites (mean 3.9 per patient) than controls (mean 2.7 per patient) [Student's $t$ test, $\mathrm{p}<0.01$ ].

Coagulase-negative staphylococci were by far the most prevalent bacteria isolated; micrococci and corynebacteria were also frequently isolated [Table I]. Sub-classification of isolates of coagulase-negative staphylococci indicated that $S$. epidermidis was the most prevalent species [Table II]. Coagulasenegative staphylococci recorded as 'Staph

Table II. Sub-classification of coagulase-negative staphylococci isolated

\begin{tabular}{lcc}
\hline Species & Lens wearers & Controls \\
\hline Staph. epidermidis & 30 & 26 \\
Staph. capitis & 10 & 6 \\
Staph. hominis & 6 & 1 \\
Staph. simulans & 4 & 4 \\
Staph. warneri & 4 & 1 \\
Staph. haemolyticus & 2 & - \\
Staph. saprophyticus & - & 1 \\
Staph. spp. & 4 & 7 \\
\hline
\end{tabular}

$s p p^{\prime}$ are those which yielded a test profile inconsistent with recognised species. ${ }^{13}$

Quantitative assessment: Histograms record the number of cfu isolated in each group from lid margins [Fig. 1], conjunctiva [Fig. 2] and tear film [Fig. 3]. Lens wearers yielded higher mean bacterial counts than did control subjects at each site sampled. These differences were statistically significant for counts from the lid margin $(U=1823, \mathrm{p}=0.033)$ and tear film $(U=1918, \mathrm{p}=0.04)$, but not from conjunctiva $(U=1964, \mathrm{p}=0.105)$. The elevation of bacterial counts from lids of lens wearers was particularly notable; eight swabs yielded counts up to 14 times higher than the maximum counts obtained from lids of control subjects (maximum counts 2,500 cfu/swab and $175 \mathrm{cfu} / \mathrm{swab}$ respectively). Corresponding figures at the other sites studied were less impressive; four conjunctival swabs from lens wearers had counts up to 2.2 times higher than all control swabs and two tear samples from lens wearers had counts up to 3.6 times higher than all tear samples from control subjects. There was no association between carriage of particularly dense bacterial populations and length of lens wear, details of lens care or any other patient-specific information obtained. No quantitative difference in the commensal population was observed between soft and hard/rigid gas-permeable lens wearers [Figs 1, 2 and 3].

There were statistically significant correla-

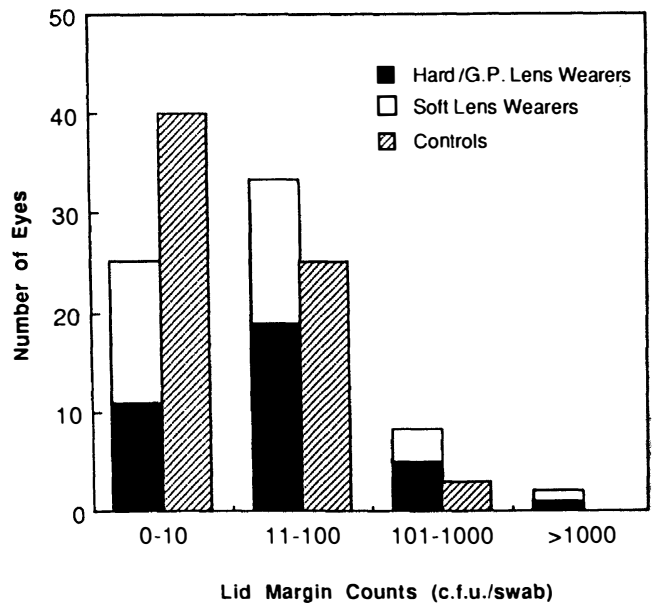

Fig. 1 Numbers of $c f u$ isolated from the lower lid margin in control and lens wearing groups. 


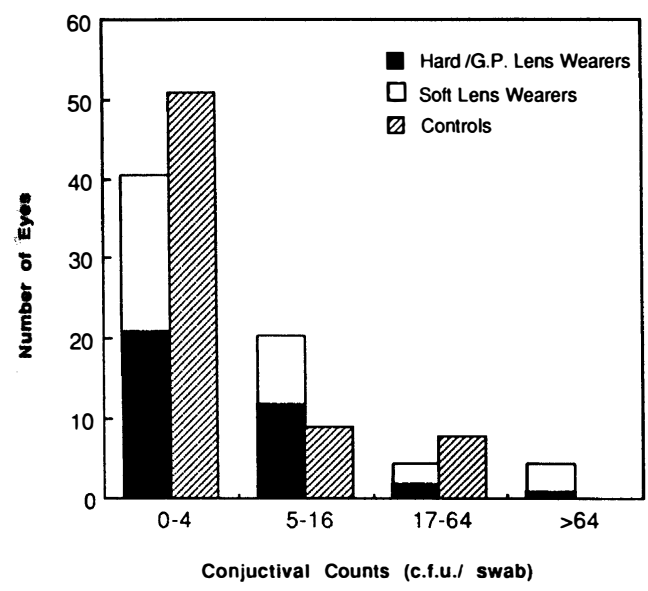

Fig. 2 Numbers of cfu isolated from inferior tarsal conjunctiva in control and lens wearing groups.

tions between counts from the three sites studied. Greatest correlation was evident in the lens wearing group: lid margin-conjunctiva $\mathrm{r}_{\mathrm{s}}=0.47(\mathrm{p}<0.001)$, lid margin-tear film $\mathrm{r}_{\mathrm{s}}=0.41(\mathrm{p}<0.001)$, conjunctiva-tear film $\mathrm{r}_{\mathrm{s}}$ $=0.40(\mathrm{p}<0.001)$. The corresponding correlation data for the control group were: lid margin-conjunctiva $\mathrm{r}_{\mathrm{s}}=0.28(\mathrm{p}=0.022)$, lid margin-tear film $r_{s}=0.34(p=0.005)$, conjunctiva-tear film $\mathrm{r}_{\mathrm{s}}=0.38(\mathrm{p}=0.001)$.

\section{Discussion}

In this study, only subjects who had been wearing lenses for a minimum of 12 months were recruited. In this way we ascertained the longer term effect of lens wear on the flora of the lid, conjunctiva and tear film.

Consistent with previous reports, we found no qualitative changes in the bacterial flora induced by lens wear. We did identify a greater number of species at all sites in lens wearers than controls. Contrary to the results of two previous surveys, ${ }^{8,9}$ we did not identify a higher proportion of Gram-negative organisms. We isolated Pseudomonas species from two controls and one lens wearer.

Quantitative changes associated with lens wear were observed Contact lens wearers yielded higher bacterial counts from each of the three sites studied than did control subjects. However the difference was substantial only at the lid margins and differences in counts noted on conjunctiva were not statistically significant. The most likely explanation for these observations is that increases in bacterial numbers on conjunctiva and in tears are due to increases in the numbers of organisms washed from the lids into the eye, and are therefore secondary to increases in lid populations. The mechanism by which lens wear might effect an increase in microbial populations on the eyelids is not readily apparent. The data presented are not likely to be explained by carry-over from lens disinfectant solutions or microbial growth around the lenses. If this were the case, the quantitative increases observed should be accompanied by qualitative shift towards Gram-negative organisms, which constitute the majority of organisms isolated from lens storage cases and various in-use lens care solutions. ${ }^{14-16}$ The observation that lens wearers did not yield significantly more Gram-negative bacteria in this study may well reflect the efficiency of host antimicrobial defences at the ocular surface rather than fastidious attention to hygiene by the subjects studied.

Carry-over from lens disinfectant solutions is a significant source of Acanthamoeba ${ }^{10}$ and Pseudomonas ${ }^{17}$ infection. Commensal bacteria provide a nutrient medium for Acanthamoeb $a^{18}$ : thus the large increases in bacterial numbers demonstrated in a small number of lens wearers might enhance the number and possibly the virulence of Acanthamoeba and hence increase the risk of keratitis in these subjects.

This study was supported in part by a grant from Alcon Laboratories Ltd.

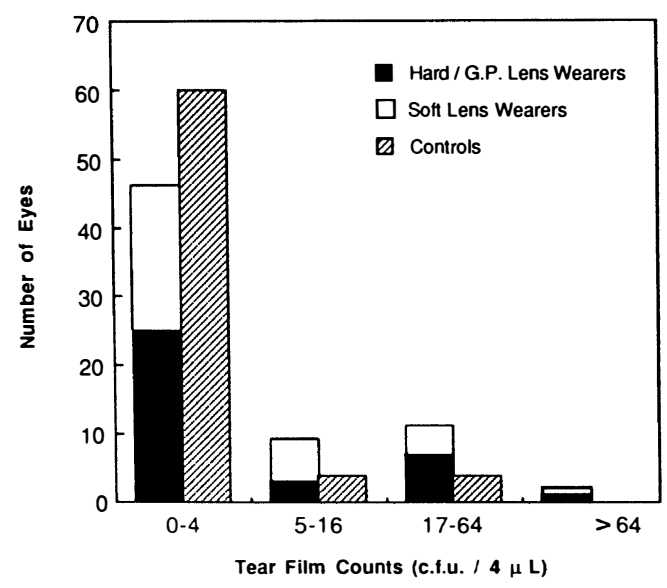

Fig. 3 Numbers of $c f u$ isolated from tear film in control and lens wearing groups. 
Key words: commensal eye flora, contact lens wear.

\section{References}

${ }^{1}$ Locatcher-Khorazo D and Seegal BC: Microbiology of the eye. St Louis. CV Mosby, 1972: 13-23.

${ }^{2}$ Allansmith MR, Ostler B, Butterworth M: Concomitance of bacteria in various areas of the eye. Arch Ophthalmol 1969, 82: 37-42.

${ }^{3}$ Noble WC: Microbiology of the human skin. 2nd ed. London. Lloyd-Luke, 1981.

${ }^{4}$ Rauschl RT and Rogers JJ: The effect of hydrophilic contact lens wear on the bacterial flora of the human conjunctiva. Int Contact Lens Clin 1978, 5: 56-62.

${ }^{5}$ McBride ME: Evaluation of the microbial flora of the eye during wear of soft contact lenses. Appl Environ Microbiol 1979, 37: 233-6.

${ }^{6}$ Smolin G, Okumoto M, Nozik RA: The microbial flora in extended-wear soft contact lens wearers. Am J Ophthalmol 1979, 88: 543-7.

${ }^{7}$ Callender MG, Tse LSY, Charles AM, Lutz D: Bacterial flora of the eye and contact lens cases during hydrogel lens wear. Am J Optom Physiol Optics 1986, 63: $177-80$.

${ }^{8}$ Hovding G: The conjunctival and contact lens bacterial flora during lens wear. Acta Ophthalmol 1981, 59: 387-401.

${ }^{9}$ Morgan JF: Complications associated with contact lens solutions. Ophthalmology 1979, 86: 1107-19.

${ }^{10}$ Centers for Disease Control: Acanthamoeba keratitis associated with contact lenses-United States. MMWR 1986, 35: 405-8.
${ }^{11}$ Moore MB, McCulley JP, Newton C, et al: Acanthamoeba keratitis: A growing problem in soft and hard contact lens wearers. Ophthalmology 1987 , 94: 1654-61.

${ }^{12}$ Cagle GD and Abshire RL: Quantitative ocular bacteriology: a method for the enumeration and identification of bacteria from the skin-lash margin and conjunctiva. Invest Ophthalmol Vis Sci 1981, 20: 751-7.

${ }^{13}$ Schleifer KH (Ed): Section 12. Gram-positive cocci. In: Sneath PHA, Mair NS, Sharpe ME, Holt JG eds. Bergey's Manual of Systematic Bacteriology, Vol 2, Baltimore: Williams and Wilkins 1986: 999-1103.

${ }^{14}$ Mayo MS, Schlitzer RL, Ward MA, Wilson LA, Ahearn DG: Association of Pseudomonas and Serratia corneal ulcers with use of contaminated solutions. J Clin Microbiol 1987, 25: 1398-400.

${ }^{15}$ Donzis PB, Mondino BJ, Weissman BA, Bruckner DA: Microbial contamination of contact lens care systems. Am J Ophthalmol 1987, 104: 325-33.

${ }^{16}$ Larkin DFP, Kilvington S, Easty DL: Contamination of contact lens storage cases by Acanthamoeba and bacteria. Br J Ophthalmol 1990, 74: 133-5.

${ }^{17}$ Mayo MS, Cook WL, Schlitzer RL, Ward MA, Wilson LA, Ahearn DG: Antibiograms, serotypes and plasmid profiles of Pseudomonas aeruginosa associated with corneal ulcers and contact lens wear. J Clin Microbiol 1986, 24: 372-6.

${ }^{18}$ Larkin DFP and Easty DL. External eye bacteria as a nutrient source for Acanthamoeba. Graefe's Arch Clin Exp Ophthalmol 1990, 228: [in press]. 